\title{
Design and Analytical Evaluation of a New Self-Centering Connection with Bolted T-Stub Devices
}

\author{
Mahbobeh Mirzaie Aliabadi, ${ }^{1}$ Mohammad Reza Bahaari, ${ }^{1}$ and Shahabeddin Torabian ${ }^{1,2}$ \\ ${ }^{1}$ School of Civil Engineering, College of Engineering, University of Tehran, P.O. Box 11365-4563, Tehran, Iran \\ ${ }^{2}$ Department of Civil Engineering, Johns Hopkins University, 3400 North Charles Street, Baltimore, MD 21218, USA \\ Correspondence should be addressed to Mahbobeh Mirzaie Aliabadi; mahbobehmirzaie@ut.ac.ir
}

Received 31 May 2013; Revised 19 September 2013; Accepted 22 September 2013

Academic Editor: Jun Liu

Copyright (C) 2013 Mahbobeh Mirzaie Aliabadi et al. This is an open access article distributed under the Creative Commons Attribution License, which permits unrestricted use, distribution, and reproduction in any medium, provided the original work is properly cited.

\begin{abstract}
A new posttensioned T-stub connection (PTTC) for earthquake resistant steel moment resisting frames (MRFs) is introduced. The proposed connection consists of high strength posttensioned (PT) strands and bolted T-stubs. The post-tensioning strands run through the column and are anchored against the flange of the exterior column. The T-stubs, providing energy dissipation, are bolted to the flange of beam and column and no field welding is required. The strands compress the T-stub against the column flange to develop the resisting moment to service loads and to provide a restoring force that returns the structure to its initial position following an earthquake. An analytical model based on fiber elements is developed in OpenSees to model PTTCs. The analytical model can predict the expected behavior of the new proposed connection under cyclic loading. PTTC provides similar characteristic behavior of the posttensioned connections. Both theoretical behavior and design methods are proposed, and the design methods are verified based on parametric studies and comparison to analytical results. The parametric studies prove the desired self-centering behavior of PTTC and show that this connection can reduce or eliminate the plastic rotation by its self-centering behavior as well as providing required strength and stiffness under large earthquake rotations.
\end{abstract}

\section{Introduction}

Post-tensioned energy dissipation (PTED) beam-to-column connections are newly proposed to be utilized as an alternative to welded connections in rigid moment frames (MRFs). They can provide required ductility and stable cyclic behavior under severe earthquakes. PTEDs main characteristics are the self-centering behavior and explicit energy dissipation capability. Self-centering addresses a rebounding capability that minimizes the residual deformations in the connection that finally results in minimal residual drift in the structure. Most of inelastic deformations and energy dissipation happens in energy dissipater (ED) devices, and the main structural elements such as beams and columns are supposed to remain elastic. EDs could be replaced in some cases after a major earthquake to make the structure ready for the next earthquake events.
Ricles et al. [1, 2] developed a self-centering beamto-column connection system in which the PT system is based on a series of high resistance steel strands running parallel to the beams whereas the ED system is composed of bolted steel top-and-seat angles. The dissipative mechanism is based on the formation of plastic hinges in each angle. The experimental results showed that reinforcing plates are necessary to control the inelastic deformation of the beams. Size and geometry of the angles influence the connection moment capacity and the energy dissipation capacity. The strands must be designed to remain elastic to provide the selfcentering and load carrying capability of the system.

Garlock et al. [3, 4] experimentally investigated six steel beam-column joint subassemblies with PT connections similar to Ricles's PT connection. A design procedure is also proposed for SMRFs with PT connections.

Christopoulos et al. [5] have experimentally studied a self-centering moment connection in which the PT system 
is composed of a couple of high resistant steel bars and other steel bars confined in steel cylinders as the ED system.

Chou et al. $[6,7]$ have proposed a PTED beam-to-column connections that consists of high resistant steel strands (PT system) and reduced flange steel plates welded to the column and bolted to the beam flanges, as ED system.

Kim and Christopoulos [8] proposed details for the gap openings accommodation along the boundaries of the slabs.

More recently, Chou et al. [9] experimentally showed that negative connection moments provided by slab reinforcements provide low residual deformations in self-centering connections. Moreover, a detail for eliminating the slab restraining effects was proposed [10].

Chou and Chen [11] evaluated the beam compression forces and column bending stiffness by modeling column deformation which resulted from gap-openings at all stories.

Inertia force transfer mechanism in self-centering moment frames has been studied via shake table and cyclic tests $[12,13]$. A three-dimensional analytical model including rotational spring has been proposed to study the effects of column bases behavior on the seismic behavior of the self-centering frames [14]. More recently, large-scale steel SC frame tests showed reasonable flag-shaped hysteresis responses [15].

Wang and Filiatrault [16] performed shake table test on two one-third scale 3-story, 2-bay steel frames (SMRF and self-centering posttensioned frame). By comparing displacement response, acceleration response, and the energy dissipation of the tested frames, improved detailing was suggested [16].

Several PTED connections based on different arrangement of the friction devices have been proposed and studied [17-19]. Rojas et al. [18] proposed a PTED connection made up of high resistance steel strands and friction devices at the top and bottom flange of the beam. An analytical model based on the fiber elements proved the connection performance in terms of strength, storey drift, local deformation and selfcentering capability [18].

Wolski et al. [19] introduced a PTED connection including a frictional ED system only below the beam bottom flange (BFFD). The detail was proposed to avoid interferences between the floor slab and the friction devices.

Tsai et al. [20] have proposed bolted web friction devices (WFDs) in PTED connections. The behavior of the isolated bolted web friction device as well as the full-scale tests on the connections including the proposed details was performed.

Lin et al. [21] developed large-scale tests of a 0.6-scale, four-story, and two-bay moment frames including web friction devices. The results showed the frame self-centered with no damage under DBE earthquake.

Finally, Dimopoulos et al. [22] have proposed a new posttensioned connection with web hourglass shape pins (WHPs). The experimental results reveal that the connection has the self-centering behavior without residual drift [22].

Several types of beam-to-column connections have been proposed to reliably implement the PTED concept in steel moment resisting frames, so far. The main differences among the proposed systems are related to the technological solutions proposed for the PT and ED systems. PT systems are based on the use of high strength steel strands or bars, whereas the ED systems are to provide yielding or friction mechanisms [1-22].

In this paper, a new posttensioned bolted T-stub connection (PTTC) for earthquake resistant steel moment resisting frames (MRFs) is proposed. The proposed connection consists of high strength posttensioned strand, as PT device, and bolted T-stubs as the ED device. The PT strands provide restoring force for self-centering behavior, while the T-stubs dissipate energy by plastic mechanisms in the T-stub flanges. The new connection requires no field welding, and the beam reinforcing plates which are common in PTED connections could be eliminated.

In the proposed PTED connection, friction devices [1821], steel bars [5], and reduced flange steel plates $[6,7]$ are replaced by $\mathrm{T}$-stubs as an energy dissipater device. The $\mathrm{T}$ stub is much more common device in the steel construction practice compared to the other devices proposed for PTEDs. Moreover, the proposed connection can be used in retrofitting and enhancement of existing nonseismic Tstub connections. According to the common shape of the connection in the construction practice, it can be assumed that the proposed connection has an easier and more economic fabrication process. It should be noted that the proposed connection is assumed to be more similar to PTED connections with top and bottom angles rather than the other types explained herein.

According to inherent characteristic of PTED connections, it is expected that the proposed connection minimizes inelastic deformation in comparison with the T-Stub moment connections without posttensioning. Both theoretical and numerical analyses are conducted to evaluate the cyclic behavior of the connection. A set of design equations are also set forth for designing PTTC connections. The selfcentering behavior of PTTC is studied using the OpenSees finite element program based on fiber elements. To verify the OpenSees models, the results are compared against the existing experimental results of a similar connection. Consequently, a detailed parametric study is performed on the designed beam-to column connections using the verified models to verify the design equations and study the selfcentering behavior of the connection with different parameters such as, initial posttensioning and number of strands.

\section{Posttensioned Bolted T-Stub Connection (PTTC)}

2.1. Connection Details. PTTC is composed up of T-stubs bolted to the beam flanges and column flange, along with posttensioned high strength strands running parallel to the beam and anchored outside of the connection as shown in Figure 1. When strands are posttensioned with initial posttensioning force, the beam flanges and the T-stubs are compressed against the column flanges. As shown in Figures 2(a) and 2(b), beam flange reinforcing plates may not be used because the T-stems provide enough stiffness to avoid premature flange buckling. Bolted T-stubs dissipate energy with developing plastic hinges in the T-stub flange. In this 


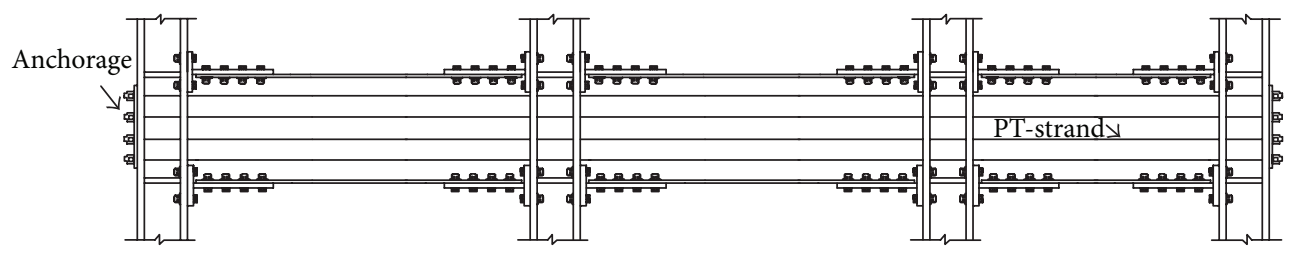

FIgURE 1: Moment resisting frame with PTTC connections.

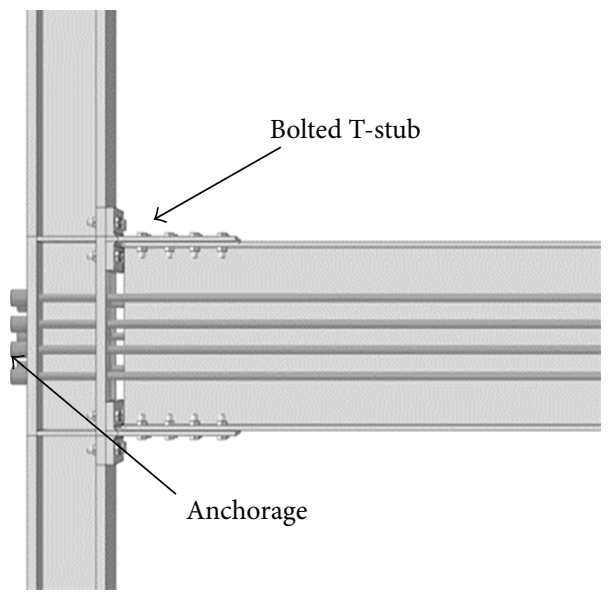

(a) Exterior connection

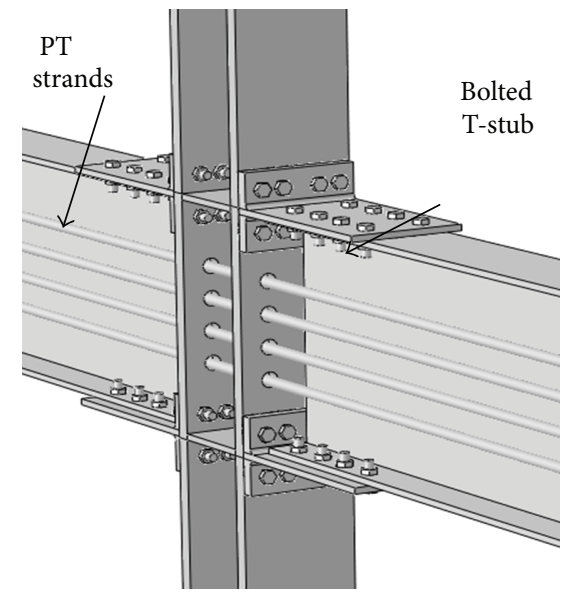

(b) Interior connection

FIgURE 2: Connection details.

section, the behavior of the energy dissipation devices (Tstubs) and PT connection is evaluated theoretically.

\subsection{Force-Deformation Relation of T-Stubs. In order to deter-} mine the contribution of the T-stubs in the connection behavior, it is necessary to determine the force-deformation relationship of the T-stub under applied loads. The forcedeformation behavior is assumed to be bilinear in tension (path o-a-b-c-d in Figure 3(b)), and no force-displacement relationship is assumed in compression following the T-stub contact. Kinematic hardening role is assumed to determine the cyclic behavior of the T-stubs, and the force-deformation relation of the T-stubs is determined according to EC3 [23]. When the applied moment overcomes the decompression moment (as defined in Section 2.3) of the connection, a gap opening occurs and the T-stub is in tension. As the moment increases, the tensile T-stub yields in tension at point (a) as shown in Figure 3(b). After yielding, point (a), the stiffness of the T-stub, decreases significantly to hardening stiffness. Unloading stiffness of the T-stubs is assumed to be equal to the elastic stiffness.

To determine the T-stub stiffness and strength parameters, two T-stubs connected by bolts are considered as shown in Figure 3(a). The initial elastic stiffness of T-stub is obtained from the initial elastic stiffness of the two T-stubs connected by bolts $\left(K_{\mathrm{T}-\mathrm{stub}-\mathrm{i}}\right)$ and is calculated as follows [23]:

$$
K_{\mathrm{T}-\mathrm{stub}-i}=\frac{1}{1 / k_{b}+1 / k_{T 1}+1 / k_{T 2}},
$$

where $k_{T 1}, k_{T 2}$ are initial stiffness of each T-stubs and $k_{b}$ is initial stiffness of bolts. Where a T-stub is connected to a rigid base (like most of the cases in T-stub to column flange connection), one of the T-stubs can be assumed to be rigid and the initial stiffness of the rigid T-stub is considered to be infinity $\left(1 / k_{T 2}=0\right)$. Consider

$$
\begin{gathered}
k_{T 2}=k_{T 1}=0.85 \frac{2 L_{\text {eff }} t_{f}^{3}}{m^{3}} \frac{(3 m+n)}{(3 m+4 n)}, \\
k_{b}=1.6 \frac{A_{s}}{L_{b}} .
\end{gathered}
$$

$L_{b}$ (bolt length) is defined based on EC3 [23]:

$$
L_{b}=t_{f 1}+t_{f 2}+2 t_{w}+\frac{1}{2\left(t_{h}+t_{n}\right)}
$$

where $A_{s}$ is the bolt area and $t_{h}, t_{n}$, and $t_{w}$ are the thicknesses of the bolt head, nut, and washer, respectively. $t_{f 1}$ and $t_{f 2}$ are the flange thickness of each T-stub. $L_{\text {eff }}$ is the effective length. $m$ is the distance between the flange-to-web plastic hinge and the bolt axis on the flange, and $n$ is the distance between the location of the bolt axis and the tip of the flange $(n \leq 1.25 \mathrm{~m})$.

Based on EC3 T-stubs have three failure modes such as Mode 1: flange yielding, Mode 2: bolt failure with flange yielding, and Mode 3: bolt failure [23]. Accordingly, the capacity of each mode can be calculated as the following [23]. 


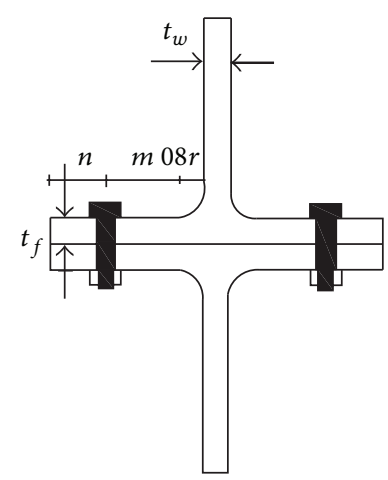

(a) Two bolted T-stubs

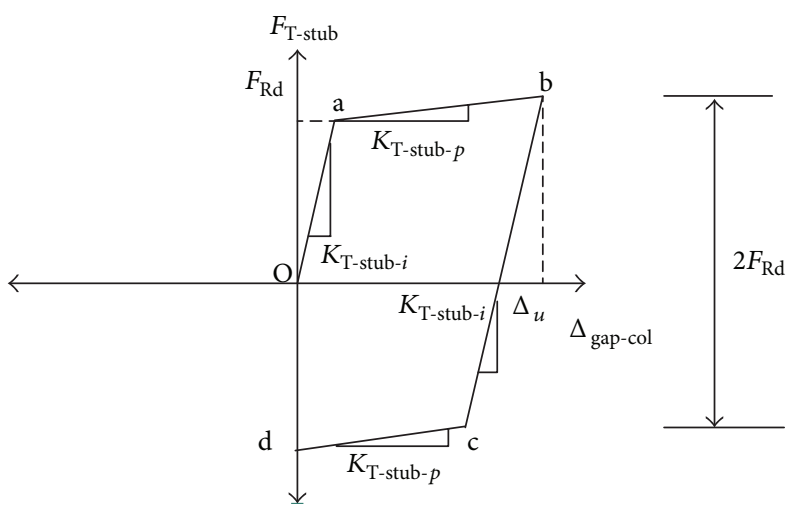

(b) Force-deformation relation of T-stubs

FIgURE 3: Behavior of T-stubs.

Mode 1, flange yielding:

$$
\begin{gathered}
F_{T, 1, R d}=\frac{4 M_{p l, R d}}{m}, \\
M_{p l, R d}=0.25 t_{f}^{2} f_{y} b_{\mathrm{eff}}, \\
b_{\mathrm{eff}}=\min \{2 \pi m, b, 4 m+1.25 n\} .
\end{gathered}
$$

Mode 2, bolt failure with flange yielding:

$$
F_{T, 2, R d}=\frac{2 M_{p l, R d}+n \sum B_{t, R d}}{m+n} .
$$

Mode 3, bolt failure:

$$
F_{T, 3, R d}=\sum B_{t, R d}
$$

where $M_{p l, R d}$ is the plastic moment resistance of the flange in bending, $B_{t, R d}$ is the resistance of the bolts in tension, $b$ is the width of the T-stub, $t_{f}$ is the flange thickness of the T-stub, and $f_{y}$ is yielding stress of the T-stub flange. The yield strength of the T-stubs, $F_{R d}$, in the force-deformation curve (point (a) in Figure 3(b)) can be estimated from (4), (7), and (8). To achieve a ductile behavior, T-stubs should be designed in Mode 1: flange yielding and higher strength should be provided for the other failure modes including bolt failure.

The inelastic stiffness of the T-stubs is obtained from

$$
K_{\mathrm{T} \text {-stub- } p}=\frac{E_{h}}{E} K_{\mathrm{T} \text {-stub-i}}
$$

where $E_{h}$ is is the strain hardening modulus and $E$ is the modulus of elasticity [24].

Finally, the ultimate force of the T-stubs $\left(F_{\mathrm{T}-\mathrm{stub}-u}\right)$ in the force-deformation curve can be estimated from (4), (7), and (8), by replacing the plastic condition with the ultimate condition. For this purpose the $M_{p l, R d}$ in (5) can be calculated based on the ultimate strength and the bolt strength should be replaced by the ultimate capacity [24].
The ultimate deformation of the T-stubs $\left(\Delta_{\text {T-stub- } u}\right)$ can be estimated from the following equation obtained from forcedeformation curve of the T-stub (Figure 3(b)):

$$
\Delta_{u}=\frac{F_{R d}}{K_{\text {T-stub- } i}}+\frac{F_{u}-F_{R d}}{K_{\text {T-stub- } p}} .
$$

2.3. Theoretical Analysis of the Cyclic Behavior of the PTTC. The idealized expected moment-rotation $M-\theta_{r}$ behaviour of a well-designed PT steel connection is shown in Figure 4, where $\theta_{r}$ is relative rotation between the beam and column (Figure 5). The $M-\theta_{r}$ behaviour of a PT connection is characterized by a gap opening, $\Delta_{\text {gap }}$, and closing at the beam-column interface under cyclic loading (Figure 5).

The moment to initiate this separation is called the decompression moment $\left(M_{d}\right)$. Using Figure 5, the decompression moment, $M_{d}$, is estimated by moment equilibrium about the point of compressive force at the compressive $\mathrm{T}$ stub (point C):

$$
M_{d}=d_{2} T_{0}
$$

$d_{2}$ is the distance between the beam centerline and the center of contact force (bottom T-stub in Figure 5) and $T_{0}$ is the total initial strand force. Notably, at the point of decomposition, relative beam-column rotation is zero and the tensile T-stub (top T-stub in Figure 5) is about losing the contact with the column face and no force is developed in that.

As shown in Figure 2(a), there is a gap between the beam web and the column face. The gap ensures the contact of the T-stubs against the column face. As shown in Figure 5, when the bottom flange is in compression, the bottom T-stub carries the compression force. Accordingly, the T-stub center of contact is reasonably assumed at the stem of the T-stub, and therefore $d_{2}$ is defined as above.

The connection moment after decompression is equal to

$$
M_{2}=M_{d}+\theta_{t} K_{1-2}^{\theta}
$$

where $K_{1-2}^{\theta}$, the connection stiffness between point (1) and (2), is the resultant of two main components: the contribution 
of the tension T-stub elastic stiffness, $K_{\mathrm{T}-\mathrm{stub}, i}^{\theta}$, and the contribution of the strand axial stiffness, $K_{s}^{\theta}$. Point (2) in Figure 4 and point (a) in Figure 3 are corresponding to the $\theta_{t}=d_{1} F_{R d} / K_{\mathrm{T}-\mathrm{stub}, i}^{\theta}$, where T-stub is yielding at point 2 . Therefore,

$$
\begin{aligned}
M_{2} & =M_{d}+\theta_{t}\left(K_{\mathrm{T}-\mathrm{stub}, i}^{\theta}+K_{s}^{\theta}\right) \\
& =M_{d}+\theta_{t}\left(K_{\mathrm{T}-\mathrm{stub}, i} d_{1}^{2}+2 d_{2}^{2}\left(\frac{K_{b} K_{s}}{K_{b}+K_{s}}\right)\right),
\end{aligned}
$$

where $K_{s}=A_{s} E / L$ is the strand stiffness and $K_{b}$ (i.e., = $\left.A_{b} E / L\right)$ is the beam stiffness. $L$ is the length of one bay, and $d_{1}$ is the distance between center of contact force and the center of the tensile T-stub. $K_{\mathrm{T}-\mathrm{stub}, i}$ can be obtained from (1).

Event 3 marks the beginning of the unloading portion of the cycle. Assuming $\theta_{3}$ is given, the moment at load reversal is

$$
M_{3}=M_{2}+\left(\theta_{3}-\theta_{t}\right) K_{2-4}^{\theta} .
$$

$K_{2-4}^{\theta}$, the stiffness between point (2) and (4) in Figure 4, is resulted from two components: the contribution of the tensile T-stub in hardening range $\left(K_{t, p}^{\theta}\right)$ and the contribution of the strand axial stiffness $\left(K_{s}^{\theta}\right)$. Consider

$$
\begin{aligned}
M_{3} & =M_{2}+\left(\theta_{3}-\theta_{t}\right)\left(K_{\mathrm{T}-\mathrm{stub}, p}^{\theta}+K_{s}^{\theta}\right) \\
& =M_{2}+\left(\theta_{3}-\theta_{t}\right)\left(K_{\mathrm{T}-\mathrm{stub}, p} d_{1}^{2}+2 d_{2}^{2}\left(\frac{K_{b} K_{s}}{K_{b}+K_{s}}\right)\right) .
\end{aligned}
$$

$K_{\text {T-stub, } p}$ can be determined using (9).

Reverse yielding of the tension T-stubs occurs at an unloading moment equal to $2\left(M_{2}-M_{d}\right)$, where the stiffness again is changed to $K_{2-4}^{\theta}$. Therefore,

$$
M_{5}=M_{3}-2\left(M_{2}-M_{d}\right) .
$$

The curve becomes vertical at event 6 where both flanges on the beam are in contact with the column and the relative angle between beam and column is zero,

$$
\begin{gathered}
M_{6}=M_{5}-\theta_{r} K_{2-4}^{\theta}, \\
M_{6}=M_{5}-\theta_{4} \times \frac{2\left(M_{2}-M_{4}\right)}{K_{1-2}^{\theta}} K_{2-4}^{\theta} .
\end{gathered}
$$

\section{Connection Design}

In this section, a step-by-step design procedure is given for design of PTTC connection.

3.1. Design Criteria. To design the proposed PTTC connection, several limit states should be satisfied, including criteria on decompression moment $\left(M_{d}\right)$, connection strength, Tstub fracture, strands yielding, and column plastic hinge.

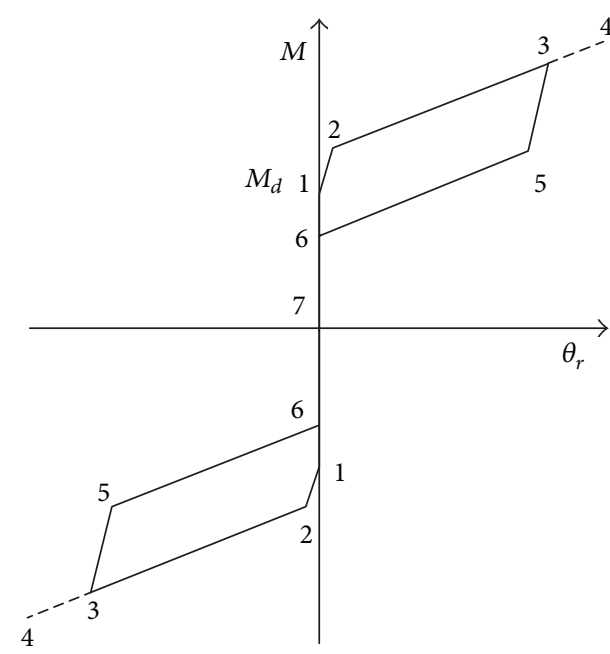

FIGURE 4: Moment-rotation behavior of posttensioned connection.

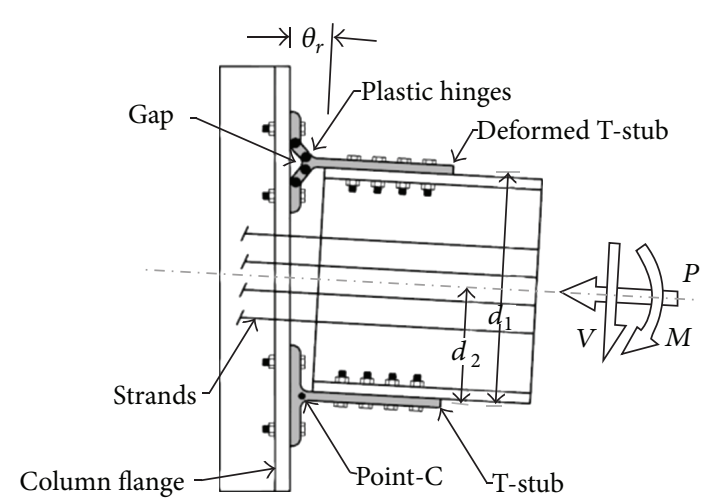

FIGURE 5: Deformation of PTTC under applied forces.

The proposed design criteria are a set of limit-state design criteria that enable the designer to design a connection based on specific column size and the beam size. These design criteria are more based on Garlock and Ricles research work; however, a simplified approach is considered to reduce the need for performing nonlinear analyses $[1,4]$.

3.1.1. Decompression Moment $\left(M_{d}\right)$ Criterion. To reduce connection permanent plastic deformation and to provide the self-centering behavior, the decompression moment should be theoretically more than $0.5 M_{t}$. However, it is experimentally showed that the decompression moment should be considered as the following for more confidence about the connection behavior [4]:

$$
M_{d} \geq 0.6 M_{t},
$$

where $M_{t}$ is the connection moment at the onset of T-stubs yielding. Connection moment initiating T-stub yielding, $\left(M_{t}\right)$, is

$$
M_{t}=d_{2} T_{0}+d_{1} F_{R d}\left(1+\frac{2 d_{2}^{2}}{K_{\mathrm{T}-\mathrm{stub}, i} d_{1}^{2}}\left(\frac{k_{b} k_{s}}{k_{b}+k_{s}}\right)\right) .
$$


3.1.2. Connection Strength Criterion. The connection moment strength at the onset of T-stub yielding is recommended to be as follows [4]:

$$
M_{t} \geq 0.55 \alpha_{a} M_{p n}
$$

where $M_{p n}$ is nominal plastic moment capacity of the beam section and $\alpha_{a}$ is a design parameter. Garlock suggested $\alpha_{a}$ taken between 0.75 and 1.2 for PT connection with reasonable strength and deformation capacity [4].

3.1.3. T-Stub Fracture Criterion. To avoid T-stub fracture, this criterion is recommended:

$$
\theta_{r, \mathrm{~T} \text {-stub } f}=\frac{\Delta_{u}}{d_{3}} \geq \theta_{r, \mathrm{DBE}}
$$

where $\theta_{r, \mathrm{~T} \text {-stub } f}$ is relative rotation causing the T-stub fracture, $\Delta_{u}$ is equal to $\Delta_{\text {gap }}$ at the T-stub fracture point (10), and $\theta_{r, \mathrm{DBE}}$ is relative rotation demand under the design base earthquake (DBE) demands. $\theta_{r, \mathrm{DBE}}$ is estimated in accordance to the amplified code-based demands [4].

3.1.4. Strand Yielding Criteria. The strands should not yield under the maximum credible earthquake (MCE) [4]:

$$
\theta_{r, s}=\frac{N_{s}\left(t_{y}-t_{0}\right)}{2 d_{2}} \frac{\left(k_{b}+k_{s}\right)}{k_{b} k_{s}} \geq \theta_{r, \mathrm{MCE}}
$$

where $\theta_{r, s}$ is relative rotation causing the strands to yield, $t_{y}$ is yield force in one strand, $t_{0}$ is initial posttensioning force in one strand, and $\theta_{r, \mathrm{MCE}}=0.04$ : is relative rotation demand under the MCE. This criterion ensures that the frame carries gravity load, even if the T-stubs fractured.

3.1.5. Column Plastic Hinge Criterion. It is common to design the columns stronger than the beams to avoid soft story mechanism.

3.2. Step-by-Step Design Procedure. The design of a frame that includes posttensioned connections is an iterative procedure, as well as all other design procedures. The preliminary beam and column sections of a PTTC frame are proportioned similar to a special moment frame (ignoring PTED characteristics) [4]. Accordingly, all "code based" provisions like strong column-weak beam criterion and system stiffness are checked using the applicable seismic code assuming rigid connections. After proportioning of the beam and column elements and designing the corresponding PTED connection, the behavior of the moment frame can be determined via a nonlinear analysis using the modeling parameters described in Section 4.

The following procedure is a step-by-step design procedure that should be considered to design a PT frame including PTTC connections.

Step 1 (Beam and Column Preliminary Proportioning). Beam and column sections of a PTTC frame are proportioned as a special moment frame since current codes do not have specific design provisions for PT frame. According to the code based analysis and design of the structure, the required parameters for connection design can be determined based on the preliminary assumptions for beam and column sections.

Step 2 (Check for Strong Column-Weak Beam Design Criterion). In this step, the selected beam and column section in the previous step should be checked for the strong column-weak beam design criterion and the flange and web slenderness limits of the AISC seismic provisions [25].

Step 3 (Check for the System Stiffness). In the third step, the frame should be checked for building code story drift limit criterion. If the building code drift limits are not satisfied, the beam and column sections must be revised to fulfill the code requirements.

Step 4 (Designing the PTTC Connection). Up to now, all the beam and column sections are determined, and therefore all beams to column connection can be designed. By knowing the beam section, the beam nominal moment capacity, $M_{p, n}$, can be calculated. In this step, the connection moment and the onset on T-stub yielding, $M_{t}$, can be determined (20).

Consequently the decompression moment $\left(M_{d}\right)$ is known from (18). By knowing the decompression moment, the initial posttensioning force of the strands $\left(T_{0}\right)$ can be calculated easily (11), and therefore the number of PT strands $\left(N_{s}\right)$ is determined from the following equation:

$$
N_{s}=\frac{T_{0}}{t_{s}}
$$

where $T_{0}$ is the total initial strand force, $N_{s}$ is the number of strands, and $t_{s}$ is the strand capacity. The selected $T_{0}$ and $N_{s}$ should satisfy strand yielding criteria in Section 3.1.4. $t_{s}$ is assumed to be $30 \%$ of the strand ultimate strength [4].

Finally, the design parameters of the T-stubs are determined based on (1)-(10). For designing T-stubs, according to EC3 [23] the plastic mechanism of the T-stub can be assumed to be developed at the flange-to-web connection or at the bolt axis or both. The prying forces developed in the bolts should be considered so that the bolt fracture does not occur. For designing T-stubs for the proposed posttensioned connection, only Mode 1: flange yielding is acceptable because bolt failure is a brittle failure mode and can affect the connection performance. The selection of the PT connection parameters is iterative. Notably, the connection panel zone should be designed as per conventional moment connections [4].

\section{Approaches for Numerical Simulation of Self-Centering Connections with T-Stubs}

Numerical simulation of the posttensioned T-stub connection (PTTC) is performed using OpenSees program, Open System for Earthquake Engineering Simulation [26]. Each structural member such as T-stub (dissipater), column, and beam is modeled by using various elements with specified 
material properties and structural behavior (see Figure 6). The connection model is made up of 6 groups of OpenSees elements. Beams and columns are modeled by linear beamcolumn elements (E1 and E2). Zero-length elements are used to model the gap (including both opening and closing) behavior, and these elements are assigned only to carry compression forces (in case of contact) without rotational stiffness (E3). Elastic-no-tension (ENT) material is used for modeling gap opening/closing behavior.

The energy dissipater elements, which in PTTC are Tstubs (E4), are assumed to be truss elements with an elasticplastic material. Truss element behavior is defined by an initial stiffness, hardening ratio, and yield stress consistent with the characteristic behavior and energy dissipation of the T-stubs. STEEL01 material is assigned to energy dissipater elements to simulate the T-stub behavior. The STEEL01 material is used to make up a uniaxial bilinear steel material.

The posttensioning strands (E5) distributed along the depth of the beam are all grouped at the beam centerline and anchored at the exterior columns (Figure 6). Strands are modeled with elastic-perfectly-plastic (EPP) truss elements.

Finally, the panel zone is modeled using a zero length rotational spring fiber element (E6) [4]. The panel zone model used in this study was developed by Krawinkler [27]. The following equations describe the model:

$$
\begin{gathered}
V_{p z, y}=0.55 \sigma_{y} d_{c}\left(t_{w}+t_{d p}\right), \\
V_{p z, u}=0.55 \sigma_{y} d_{c} t_{w}\left(1+\frac{3.45 t_{c f}^{2} b_{c}}{d_{b} d_{c} t_{w}}\right) \\
+\frac{\sigma_{y}}{\sqrt{3}}\left(d_{c}-t_{c f}\right) t_{d p}, \\
\gamma_{p z, y}=\frac{\sigma_{y} / \sqrt{3}}{G},
\end{gathered}
$$

where $V_{p z, y}$ and $\gamma_{p z, y}$ are the panel zone shear force deformation at the yield point, respectively. The ultimate panel zone shear $V_{p z, u}$ is assumed to occur at a deformation of $4 \gamma_{p z, y} . \sigma_{y}$ is the yield stress of the column material, and $d_{b}$, $d_{c}, t_{w}, t_{c f}, t_{d p}$, and $b_{c}$ are the beam depth, column depth, column web thickness, column flange thickness, total doubler plate thickness, and column width, respectively. $\gamma_{p z, y}$ is only a function of the material properties and not the panel zone geometry as described in (25).

To model the depth of beams and columns, rigid-links (E7) are placed between the zero-length elements and the nodes of column-beam elements.

\section{Verification of the Connection Model}

Both T-stub and angle energy dissipaters used in posttensioned connections are providing yielding mechanisms for dissipating energy through formation of plastic hinges in EDs. Three unsymmetrical plastic hinges are formed in the angles [3]: two on the angle leg connected to the column, and one on the angle leg connected to the beam. However, T-stubs form four symmetric plastic hinges: two plastic hinges in the

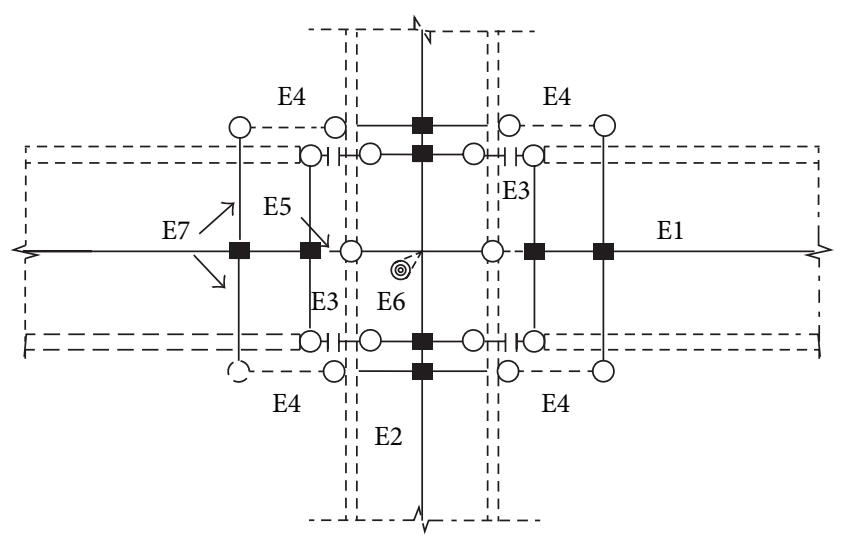

FIgURE 6: Modeling of posttensioned T-stub connections in OpenSees.

flange plates close to bolt holes and two in the flange plates close to the stem as shown in Figure 5 [23]. Formation of four plastic hinges in T-stubs provides more energy dissipation capacity for T-stubs compared to angles. Furthermore, Tstubs can provide higher strength as an ED device where higher moment capacity is needed to connect deeper beams to column by PTED connections.

To evaluate the accuracy of the OpenSees analytical models for simulating PTTC behavior, same modeling assumptions are adopted to model posttensioned connections with angle ED devices. From modeling point of view, the difference between two systems (PT connection with angles and Tstubs) is reflected in modeling properties of E4 element and STEEL01 material. The modeling results are then compared to test results conducted by the Garlock et al. [3]. The Connection details and test setup are shown in Figure 7. All 6 test specimens were cruciform-shaped beam-column subassemblages that simulated an interior joint in a moment resisting frame. Dimensions, sizes, and detailed properties of the test specimens are tabulated in Table 1 . The momentrelative rotation response behavior predicted by OpenSees is compared with test results for PT connection (36s-20-P and 16s-45) in Figure 8. The OpenSees numerical results are in good agreement with the experimental results. Therefore, the modeling methodology and assumptions are adopted for modeling PTTC in the following section.

\section{Modeling Parameters for the New Connection (PTTC)}

To model the new proposed connection, all modeling properties are adopted similar to the models in the previous section. The size of beams and columns is presented in Table 2. The nominal yield strength $\left(\sigma_{y}\right)$ for beams and columns is considered to be $345 \mathrm{MPa}$. Height of all columns is $3962 \mathrm{~mm}$, and the combined length of the specimens including column depth and the length of the two beams is $8992 \mathrm{~mm}$ according to Garlock et al. test setup [3]. Size and geometry of the Tstubs designed in accordance the design procedure of with Section 3 is tabulated in Table 3 . The tensile capacity and 
TABLE 1: Test matrix (Garlock et al.) [3].

\begin{tabular}{|c|c|c|c|c|c|}
\hline Specimen $N_{s}-T$ & Column section & Beam section & Angle size & $N_{s}$ & $T_{0}(\mathrm{kN})$ \\
\hline $20 \mathrm{~s}-18$ & $W 14 \times 398$ & $W 36 \times 150$ & $L 8 \times 8 \times 3 / 4$ & 20 & 1526 \\
\hline $20 s-18 w$ & $W 14 \times 398$ & $W 36 \times 150$ & $L 8 \times 8 \times 3 / 4$ & 20 & 1312 \\
\hline $16 s-45$ & $W 14 \times 398$ & $W 36 \times 150$ & $L 8 \times 8 \times 3 / 4$ & 16 & 3051 \\
\hline $36 s-30$ & $W 14 \times 398$ & $W 36 \times 150$ & $L 8 \times 8 \times 3 / 4$ & 36 & 4728 \\
\hline 36 s-20-P & $W 14 \times 398$ & $W 36 \times 150$ & $L 8 \times 8 \times 3 / 4$ & 36 & 3194 \\
\hline 36 s-30-P & $W 14 \times 398$ & $W 36 \times 150$ & $L 8 \times 8 \times 3 / 4$ & 36 & 4759 \\
\hline
\end{tabular}

$N_{s}$ : number of strands, $T$ : initial force in kips (per strands).

TABLE 2: PTTC specimens.

\begin{tabular}{|c|c|c|c|c|c|c|c|c|c|c|}
\hline Type & Beam & Column & $Z_{b}\left(\mathrm{~cm}^{3}\right)$ & $M_{P, n}(\mathrm{kN} \cdot \mathrm{m})$ & $\alpha_{a}$ & $M_{t}(\min )(\mathrm{kN} \cdot \mathrm{m})$ & $M_{d}(\min )(\mathrm{kN} \cdot \mathrm{m})$ & $d_{2}(\mathrm{~cm})$ & $T_{0}(\mathrm{kN})$ & $N_{s}$ \\
\hline S1 & $W 30 \times 173$ & $W 14 \times 426$ & 9946.9 & 3432 & 1.2 & 2265 & 1359 & 38.6 & 3519 & 30 \\
\hline S2 & $W 30 \times 173$ & $W 14 \times 426$ & 9946.9 & 3432 & 0.95 & 1793 & 1076 & 38.6 & 2786 & 30 \\
\hline S3 & $W 30 \times 173$ & $W 14 \times 426$ & 9946.9 & 3432 & 0.75 & 1416 & 849 & 38.6 & 2199 & 30 \\
\hline S4 & $W 36 \times 150$ & $W 14 \times 311$ & 9520.9 & 3284.7 & 1.2 & 2167 & 1300 & 45.6 & 2852 & 30 \\
\hline S5 & $W 36 \times 150$ & $W 14 \times 311$ & 9520.9 & 3284.7 & 0.95 & 1716 & 1029 & 45.6 & 2258 & 30 \\
\hline S6 & $W 36 \times 150$ & $W 14 \times 311$ & 9520.9 & 3284.7 & 0.75 & 1355 & 813 & 45.6 & 1783 & 20 \\
\hline S7 & $W 36 \times 150$ & $W 14 \times 311$ & 9520.9 & 3284.7 & 0.75 & 1355 & 813 & 45.6 & 1783 & 30 \\
\hline S8 & $W 36 \times 170$ & $W 14 \times 370$ & 10946.6 & 3776.5 & 1.2 & 2493 & 1496 & 45.9 & 3253 & 60 \\
\hline S9 & $W 36 \times 170$ & $W 14 \times 370$ & 10946.6 & 3776.5 & 0.95 & 1973 & 1184 & 45.9 & 2575 & 60 \\
\hline S10 & $W 36 \times 170$ & $W 14 \times 370$ & 10946.6 & 3776.5 & 0.75 & 1558 & 935 & 45.9 & 2033 & 60 \\
\hline S11 & $W 36 \times 232$ & $W 14 \times 605$ & 15338.3 & 5292 & 0.95 & 2765 & 1659 & 47.1 & 3522 & 40 \\
\hline S12 & $W 36 \times 232$ & $W 14 \times 605$ & 15338.3 & 5292 & 0.95 & 2765 & 1659 & 47.1 & 3522 & 50 \\
\hline $\mathrm{S} 13$ & $W 36 \times 232$ & $W 14 \times 605$ & 15338.3 & 5292 & 0.95 & 2765 & 1659 & 47.1 & 3522 & 60 \\
\hline
\end{tabular}

$M_{P, n}$ : Plastic moment capacity of the beam section.

$Z_{b}$ : Plastic modulus.

TABLE 3: Size and geometry of T-stubs.

\begin{tabular}{lccccc}
\hline Type of T-stub & Flange thickness $(\mathrm{mm})$ & Web thickness $(\mathrm{mm})$ & Bolt diameter $(\mathrm{mm})$ & Bolt material & $\sigma_{y}(\mathrm{MPa})$ \\
\hline $\mathrm{A}$ & 25 & 15 & 25.4 & $\mathrm{~A} 490$ & 345 \\
$\mathrm{~B}$ & 30 & 15 & 25.4 & $\mathrm{~A} 490$ & 345 \\
\hline
\end{tabular}

TABLE 4: Response of analysis.

\begin{tabular}{|c|c|c|c|c|c|c|}
\hline Type & Beam & $T_{0}(\mathrm{kN})$ & $N_{s}$ & T-stub & $M_{d} / M_{p, n}$ & $T_{0} / T_{u}$ \\
\hline S1 & $W 30 \times 173$ & 3519 & 30 & B & 0.39 & 0.46 \\
\hline S2 & $W 30 \times 173$ & 2786 & 30 & B & 0.31 & 0.35 \\
\hline S3 & $W 30 \times 173$ & 2199 & 30 & B & 0.24 & 0.28 \\
\hline S4 & $W 36 \times 150$ & 2852 & 30 & A & 0.39 & 0.36 \\
\hline S5 & $W 36 \times 150$ & 2258 & 30 & A & 0.31 & 0.29 \\
\hline S6 & $W 36 \times 150$ & 1783 & 20 & A & 0.24 & 0.34 \\
\hline S7 & $W 36 \times 150$ & 1783 & 30 & A & 0.24 & 0.22 \\
\hline S8 & $W 36 \times 170$ & 3253 & 60 & B & 0.39 & 0.21 \\
\hline S9 & $W 36 \times 170$ & 2575 & 60 & B & 0.31 & 0.16 \\
\hline S10 & $W 36 \times 170$ & 2033 & 60 & B & 0.24 & 0.13 \\
\hline S11 & $W 36 \times 232$ & 3522 & 40 & B & 0.31 & 0.33 \\
\hline S12 & $W 36 \times 232$ & 3522 & 50 & B & 0.31 & 0.27 \\
\hline $\mathrm{S} 13$ & $W 36 \times 232$ & 3522 & 60 & B & 0.31 & 0.22 \\
\hline
\end{tabular}




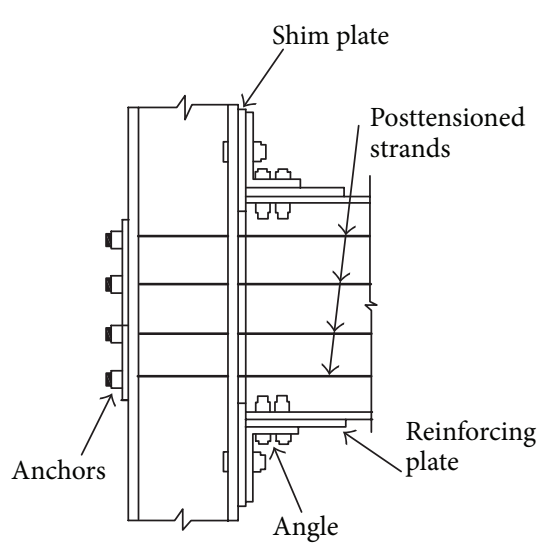

(a) Connection details and

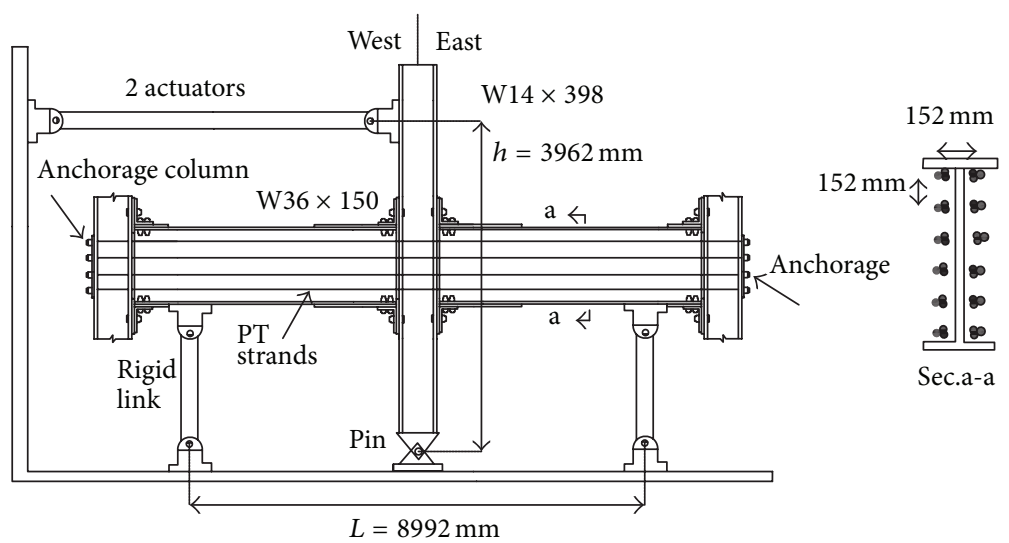

(b) test setup

FIGURE 7: Garlock's experiments [3].

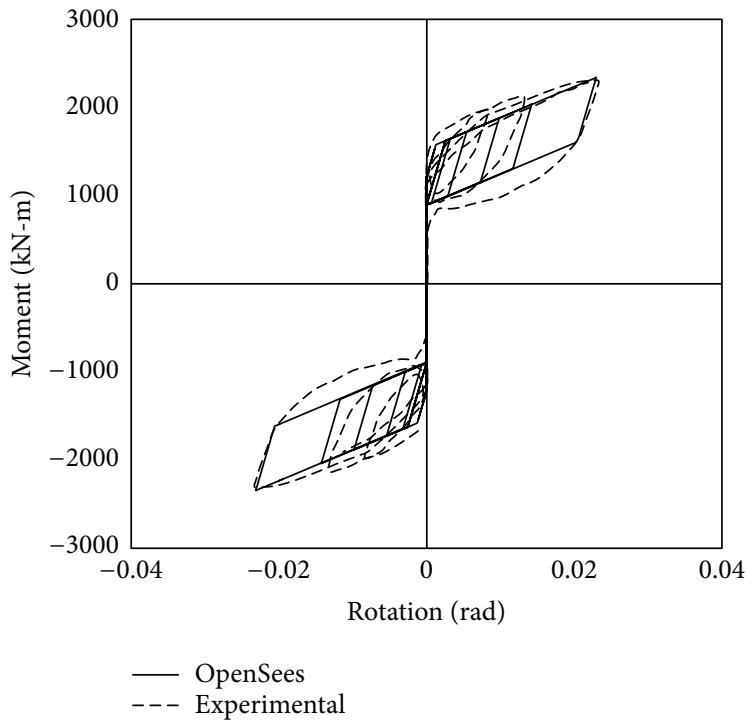

(a) $16 \mathrm{~s} 45$ model

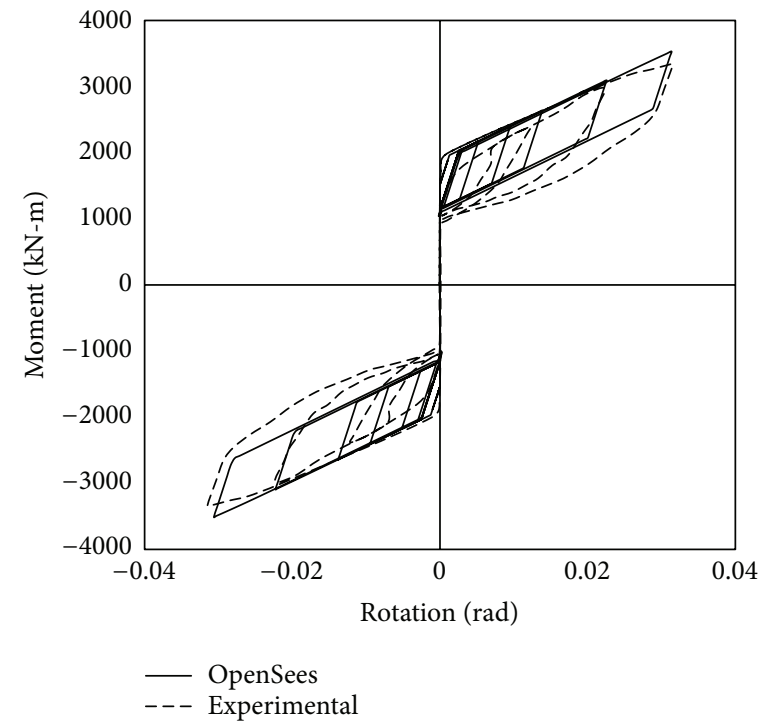

(b) $36 \mathrm{~s} 20$ model

FIGURE 8: OpenSees and experimental results.

the modulus of elasticity of strands are $266 \mathrm{kN}$ and $199 \mathrm{GPa}$, respectively. The yielding force of the strands is $230 \mathrm{kN}$, and the nominal area of each strand is $140 \mathrm{~mm}^{2}$ [4].

\section{Parametric Studies on the Designed Specimens}

To investigate effects of the connection details on the behavior of the proposed connection, several parameters including beam size, $\alpha_{a}$, number of strands, and initial posttensioning force are considered in a numerical study on the designed PTTC connections listed in Table 2. Each model consistes of a cruciform-shaped beam-column subassemblage that simulates an interior joint in a moment resisting frame. The SAC standard cyclic loading protocol is applied to the specimens in accordance with FEMA350 [28]. The numerically resulted decompression moment, $M_{d}$, normalized by the nominal plastic moment capacity, is tabulated in Table 4 .

7.1. Effects of Initial Posttensioning $\left(T_{0}\right)$ or $\alpha_{a}$. Effect of $T_{0}$ on the connection behavior is illustrated in terms of $M$ versus $\theta_{r}$ in Figure 9, where $M$ is the moment of the east beam at the column face. Specimens (S8, S9, and S10) have different $T_{0}$ values $(3253,2575$, and $2033 \mathrm{kN}$, resp.) which corresponded to different $\alpha_{a}$ but the same number of $N_{s}$ and $A_{s}$. The decompression moments are $0.39 M_{p}, 0.31 M_{p}$, and $0.24 M_{p}$ for PT connections S8, S9, and S10, respectively. S8 with the largest posttensioning force provides relatively larger connection moment for a given $\theta_{r}$ compared to $S 9$ and $S 10$ as shown in Figure 9.

According to Figure 10, specimen S4 $\left(T_{0}=2852 \mathrm{kN}\right)$ has larger moment values than S5 $\left(T_{0}=2258 \mathrm{kN}\right)$. The same results are illustrated in Figure 11 for specimens S1, S2, and S3. 


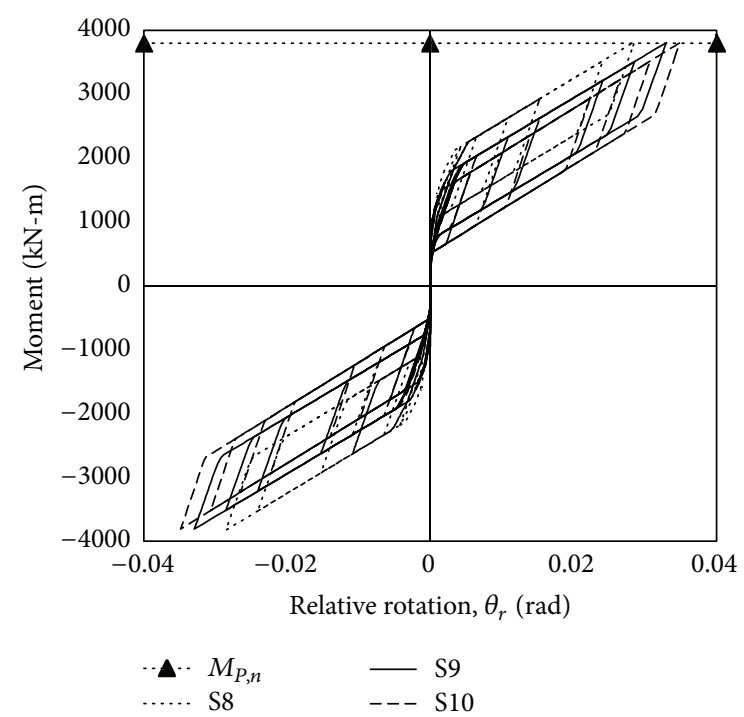

FIGURE 9: Moment-relative rotation response specimens S8, S9, and S10.

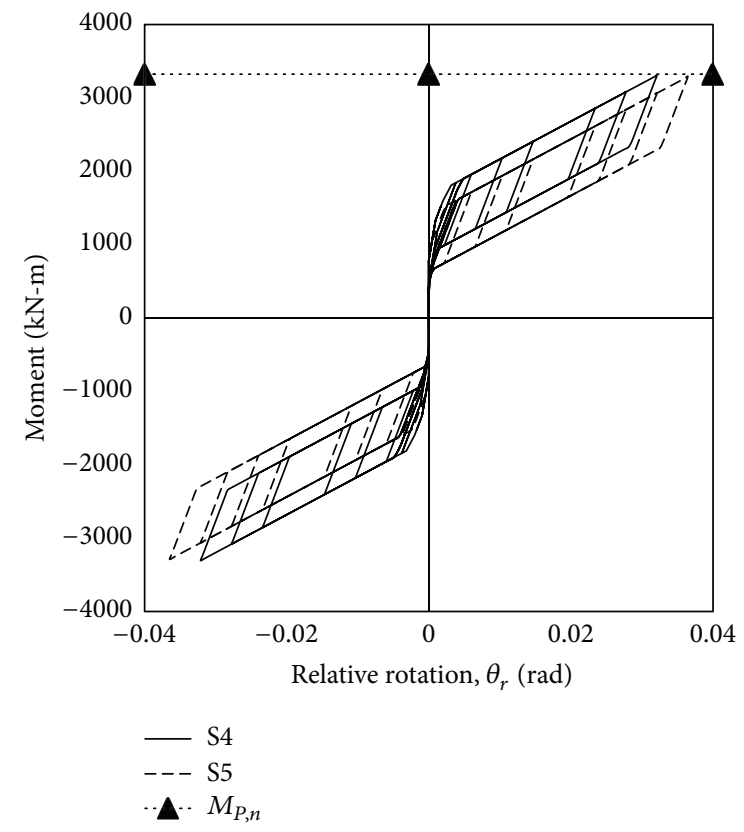

FIGURE 10: Moment-relative rotation response specimens S4 and S5.

For all of the specimens the larger posttensioning force resulted in larger moment capacity.

7.2. Effects of the Number of Strands. The axial stiffness of the strands (which is directly proportional to $N_{s}$ and $A_{s}$ ) mostly contributes to the stiffness of the connection after decompression. This can be seen by comparing the $M-\theta_{r}$ plots for S6 (with 20 strands) and S7 (with 30 strands) in Figure 12 . These specimens has essentially the same $T_{0}$ value (and therefore the same $M_{d}$ ) but different number of strands $N_{s}$ (Table 4). As shown in Figure 12, after decompression the stiffness of S7 is greater than that of S6. The connection

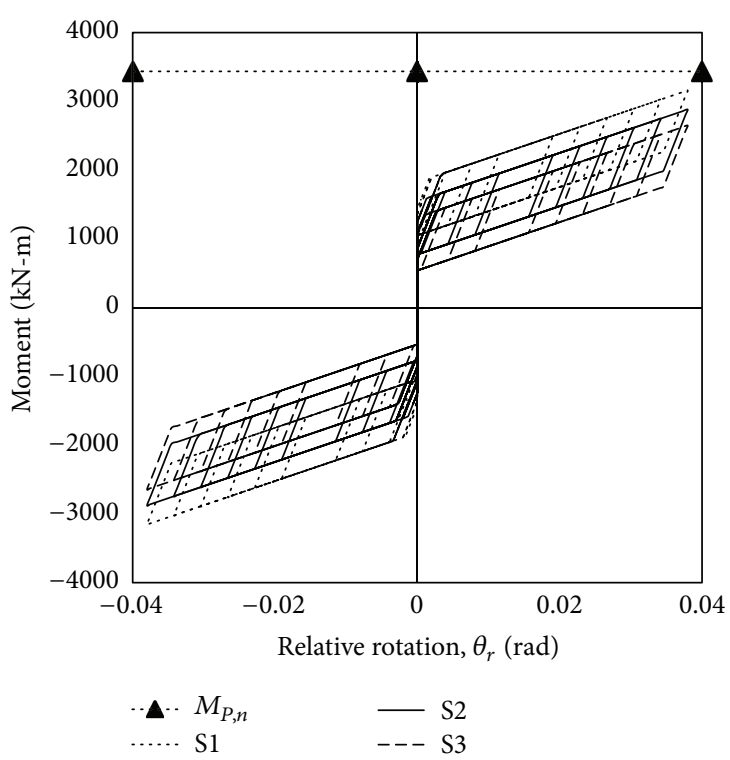

FIGURE 11: Moment-relative rotation response specimens S1, S2, and S3.

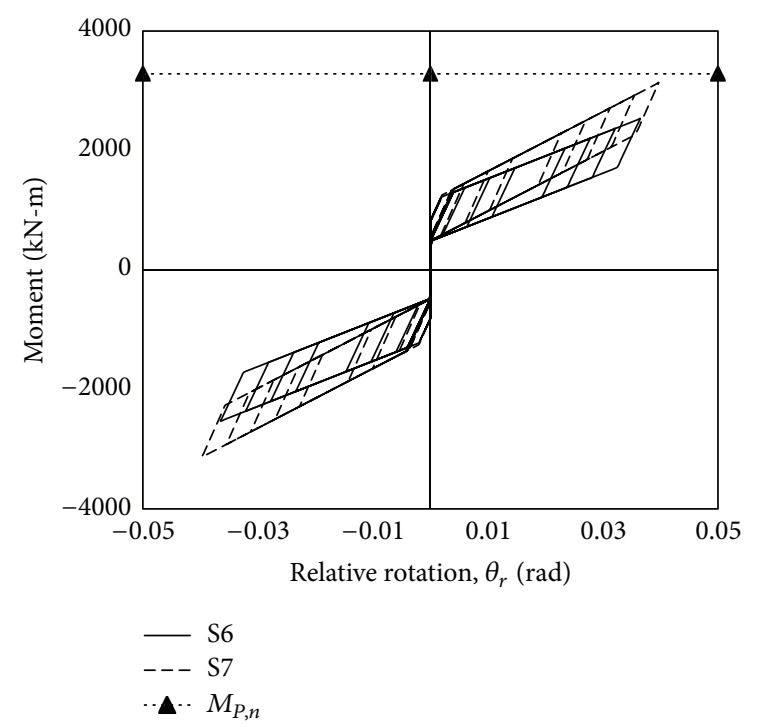

FIGURE 12: Moment-relative rotation response S6 and S7.

with larger number of strands (S7) has greater strength due to larger stiffness after decompression and have greater deformation capacity for a smaller initial force per strands.

Same results are shown in Figure 13 for S11, S12, and S13. These specimens have the same $T_{0}$ value but different number of strands (Table 4). Figure 13 shows that after decompression, the stiffness of specimen (S13) is greater than that of specimens (S11 and S12).

The relationship between strand forces normalized by the strand capacity $\left(T_{u}\right)$ versus relative rotations is shown in Figure 14 for S6 and S7. As shown, the strands remained elastic throughout the analyses. The specimen S6 is vulnerable to fracture under cyclic loading where $T_{\max } / T_{u}=0.72$. 


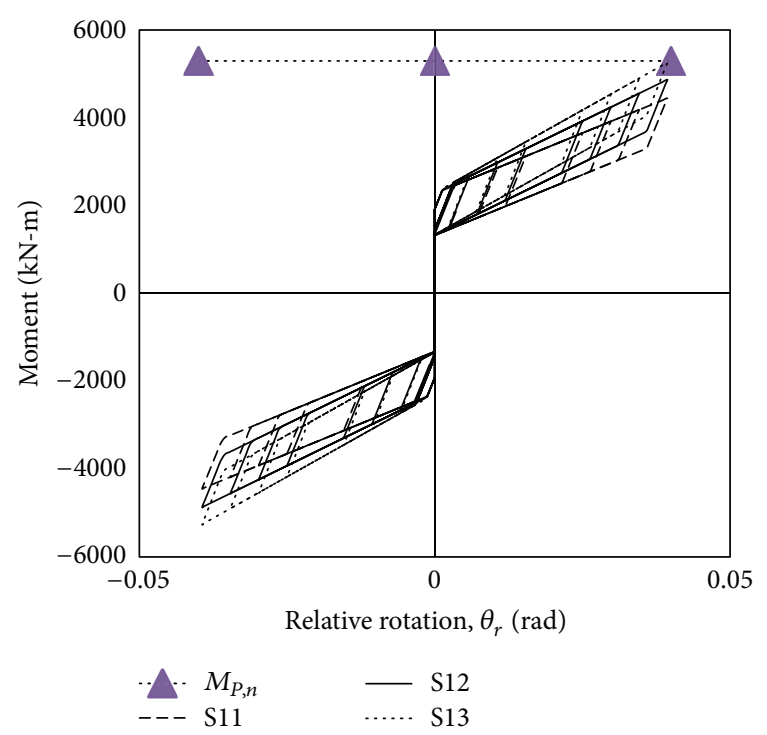

FIGURE 13: Moment-relative rotation response S11, S12, and S13.

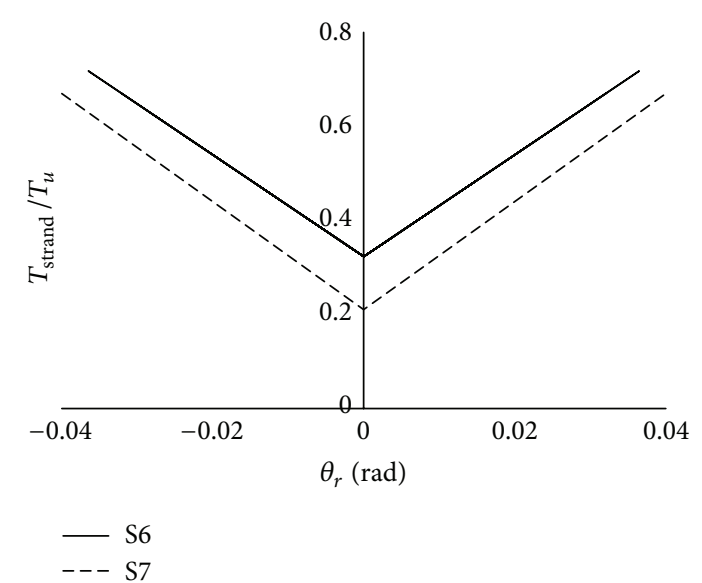

FIGURE 14: Strand behavior (S6, S7).

Therefore, the connections with more strands may have better seismic behavior and the strands yield at high rotations.

\section{Summary and Conclusions}

A new posttensioned connection for seismic resistant steel frame structures that requires no field welding has been presented. Combining bolted T-stubs with high strength PT strands results in a connection with an initial stiffness that is similar to fully welded moment resisting connections. In addition, the connection has a self-centering capability, resulting in minimal permanent story drift in a building following a severe earthquake. An analytical model based on fiber elements is developed which accurately predicts the behavior of a PTTC under cyclic loading. The model is used for parametric analytical study of the effects of connection details on the behavior of interior connection subassemblages. The details investigated include (1) the level of posttensioning force, (2) number of strands, and (3) $\alpha_{a}$. The result showed that increasing the initial posttensioning force and $\alpha_{a}$ increases the decompression moment and the moment capacity of the connection. However, an excessive post- tensioning force results in yielding of the PT strands. It is shown that using larger number of strands in the connection prevents strand yielding criteria and increases $\theta_{\max }$ and strength of connection.

\section{References}

[1] J. M. Ricles, R. Sause, M. M. Garlock, and C. Zhao, "Posttensioned seismic-resistant connections for steel frames," Journal of Structural Engineering, vol. 127, no. 2, pp. 113-121, 2001.

[2] J. M. Ricles, R. Sause, S. W. Peng, and L. W. Lu, "Experimental evaluation of earthquake resistant posttensioned steel connections," Journal of Structural Engineering, vol. 128, no. 7, pp. 850859, 2002.

[3] M. M. Garlock, J. M. Ricles, and R. Sause, "Experimental studies of full-scale posttensioned steel connections," Journal of Structural Engineering, vol. 131, no. 3, pp. 438-448, 2005.

[4] M. M. Garlock, R. Sause, and J. M. Ricles, "Behavior and design of posttensioned steel frame systems," Journal of Structural Engineering, vol. 133, no. 3, pp. 389-399, 2007.

[5] C. Christopoulos, A. Filiatrault, C. M. Uang, and B. Folz, "Posttensioned energy dissipating connections for moment-resisting steel frames," Journal of Structural Engineering, vol. 128, no. 9, pp. 1111-1120, 2002.

[6] C. C. Chou, J. H. Chen, Y. C. Chen, and K. C. Tsai, "Evaluating performance of post-tensioned steel connections with strands and reduced flange plates," Earthquake Engineering and Structural Dynamics, vol. 35, no. 9, pp. 1167-1185, 2006.

[7] C. C. Chou and C. C. Wu, "Performace evaluation of steel reduced flange plate moment connections," Earthquake Engineering and Structural Dynamics, vol. 36, no. 14, pp. 2083-2097, 2007.

[8] H. J. Kim and C. Christopoulos, "Seismic design procedure and seismic response of post-tensioned self-centering steel frames," Earthquake Engineering and Structural Dynamics, vol. 38, no. 3, pp. 355-376, 2009.

[9] C. C. Chou, Y. C. Wang, and J. H. Chen, "Seismic design and behavior of post-tensioned steel connections including effects of a composite slab," Engineering Structures, vol. 30, no. 11, pp. 3014-3023, 2008.

[10] C. C. Chou, K. C. Tsai, and W. C. Yang, "Self-centering steel connections with steel bars and a discontinuous composite slab," Earthquake Engineering and Structural Dynamics, vol. 38, no. 4, pp. 403-422, 2009.

[11] C. C. Chou and J. H. Chen, "Column restraint in post-tensioned self-centering moment frames," Earthquake Engineering and Structural Dynamics, vol. 39, no. 7, pp. 751-774, 2010.

[12] C. C. Chou and J. H. Chen, "Seismic design and shake table tests of a steel post-tensioned self-centering moment frame with a slab accommodating frame expansion," Earthquake Engineering and Structural Dynamics, vol. 40, no. 11, pp. 1241-1261, 2011.

[13] C. C. Chou and J. H. Chen, "Development of floor slab for steel post-tensioned self-centering moment frames," Journal of Constructional Steel Research, vol. 67, no. 10, pp. 1621-1635, 2011. 
[14] C. C. Chou and J. H. Chen, "Analytical model validation and influence of column bases for seismic responses of steel posttensioned self-centering MRF systems," Engineering Structures, vol. 33, no. 9, pp. 2628-2643, 2011.

[15] C. C. Chou and J. H. Chen, "Tests and analyses of a full-scale post-tensioned RCS frame subassembly," Journal of Constructional Steel Research, vol. 66, no. 11, pp. 1354-1365, 2010.

[16] D. Wang and A. Filiatrault, "Shake table testing of a selfcentering post-tensioned steel frame," in Proceedings of the 14th World Conference on Earthquake Engineering, Beijing, China, October 2008.

[17] B. G. Morgen and Y. C. Kurama, "A friction damper for posttensioned precast concrete moment frames," PCI Journal, vol. 49, no. 4, pp. 112-133, 2004.

[18] P. Rojas, J. M. Ricles, and R. Sause, "Seismic performance of post-tensioned steel moment resisting frames with friction devices," Journal of Structural Engineering, vol. 131, no. 4, pp. 529-540, 2005.

[19] M. Wolski, J. M. Ricles, and R. Sause, "Experimental study of a self-centering beam-column connection with bottom flange friction device," Journal of Structural Engineering, vol. 135, no. 5, pp. 479-488, 2009.

[20] K. C. Tsai, C. C. Chou, C. L. Lin, P. C. Chen, and S. J. Jhang, "Seismic self-centering steel beam-to-column moment connections using bolted friction devices," Earthquake Engineering and Structural Dynamics, vol. 37, no. 4, pp. 627-645, 2008.

[21] Y. C. Lin, J. M. Ricles, and R. Sause, "Earthquake simulations on a self-centering steel moment resisting frame with web friction devices," in Proceedings of The 14th World Conference on Earthquake Engineering, Beijing, China, 2008.

[22] A. Dimopoulos, T. Karavasilis, and G. Vasdravellis, "Seismic design, modeling and assessment of self-centering steel frames using post-tensioned connections with web hourglass shape pins," Bulletin of Earthquake Engineering, vol. 11, no. 5, pp. 17971816, 2013.

[23] "Part 1.8: design of joints, stage 49 drafts," in Eurocode 3: Design of Steel Structures, European Committee for Standardization, Brussels, Belgium, 2003.

[24] A. M. G. Coelho, L. S. Silva, and S. K. Bijlaard, Characterization of the Nonlinear Behavior of Single Bolted T-Stub Connections, Connections in Steel Structures V, Amsterdam, The Netherlands, 2004.

[25] American Institute of Steel Construction, Seismic Provisions for Structural Steel Buildings, AISC, Chicago, Ill, USA, 2005.

[26] F. McKenna, G. L. Fenves, and M. H. Scott, Open System for Earthquake Engineering Simulation, University of California, Berkeley, Calif, USA, 2000, http://opensees.berkeley.edu/.

[27] H. Krawinkler, "Shear in beam-column joints in seismic design of steel frames," Engineering Journal, vol. 15, no. 3, pp. 82-91, 1978.

[28] Federal Emergency Management Agency (FEMA), Recommended Seismic Design Criteria for New Steel Moment Frame Buildings, FEMA-350, The SAC Joint Venture for FEMA, Washington, DC, USA, 2000. 

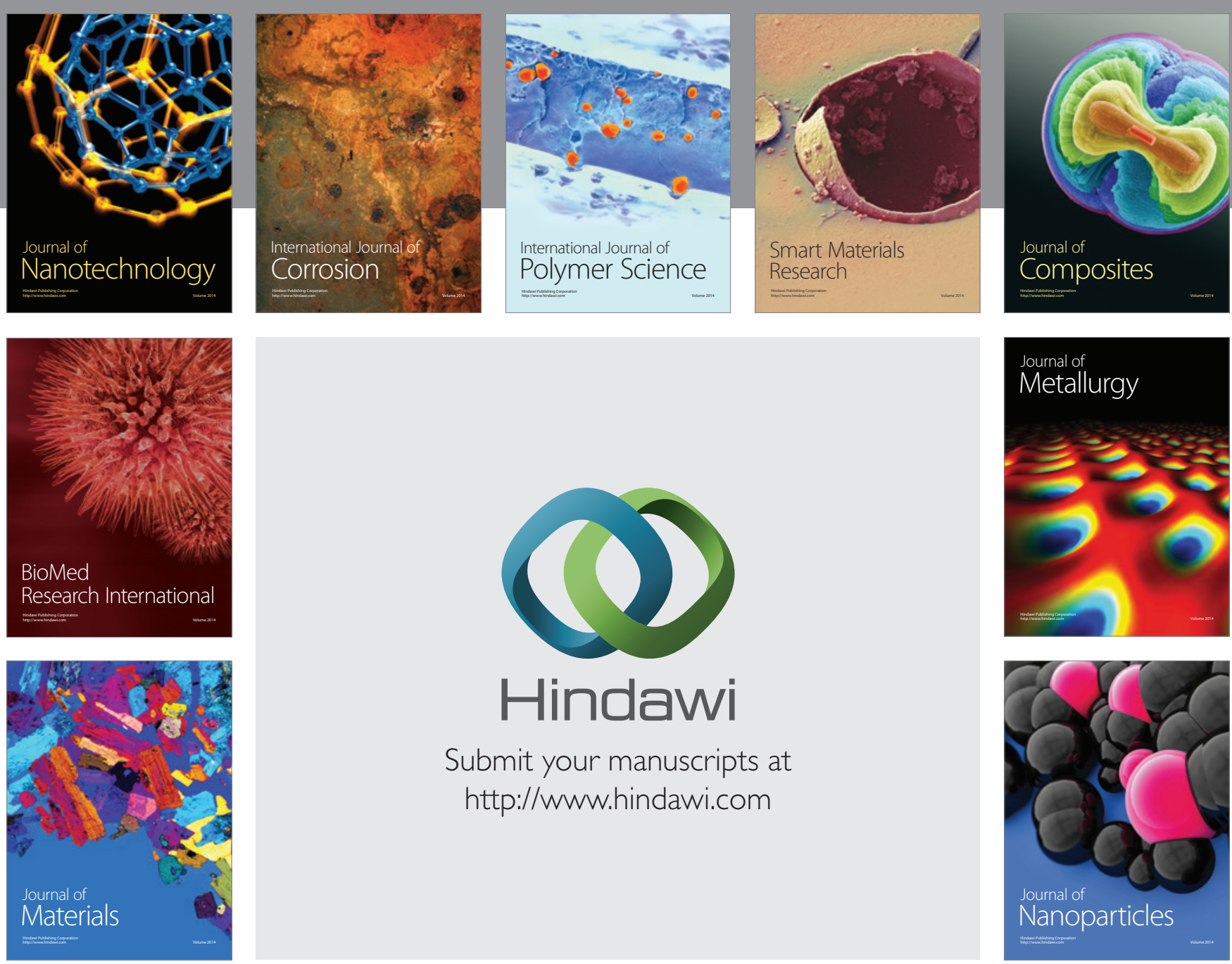

Submit your manuscripts at http://www.hindawi.com
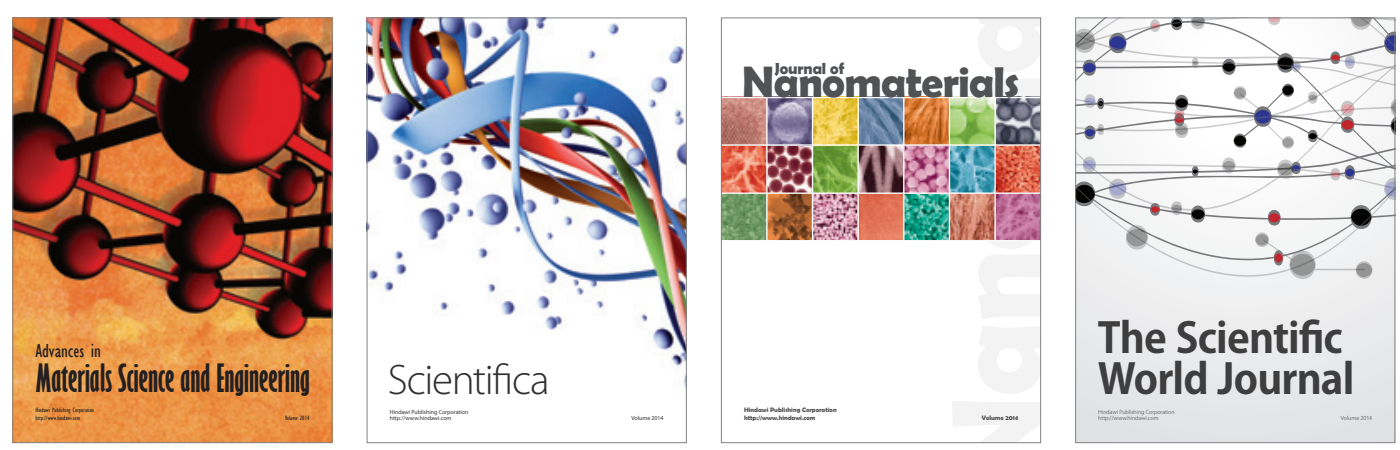

\section{The Scientific World Journal}
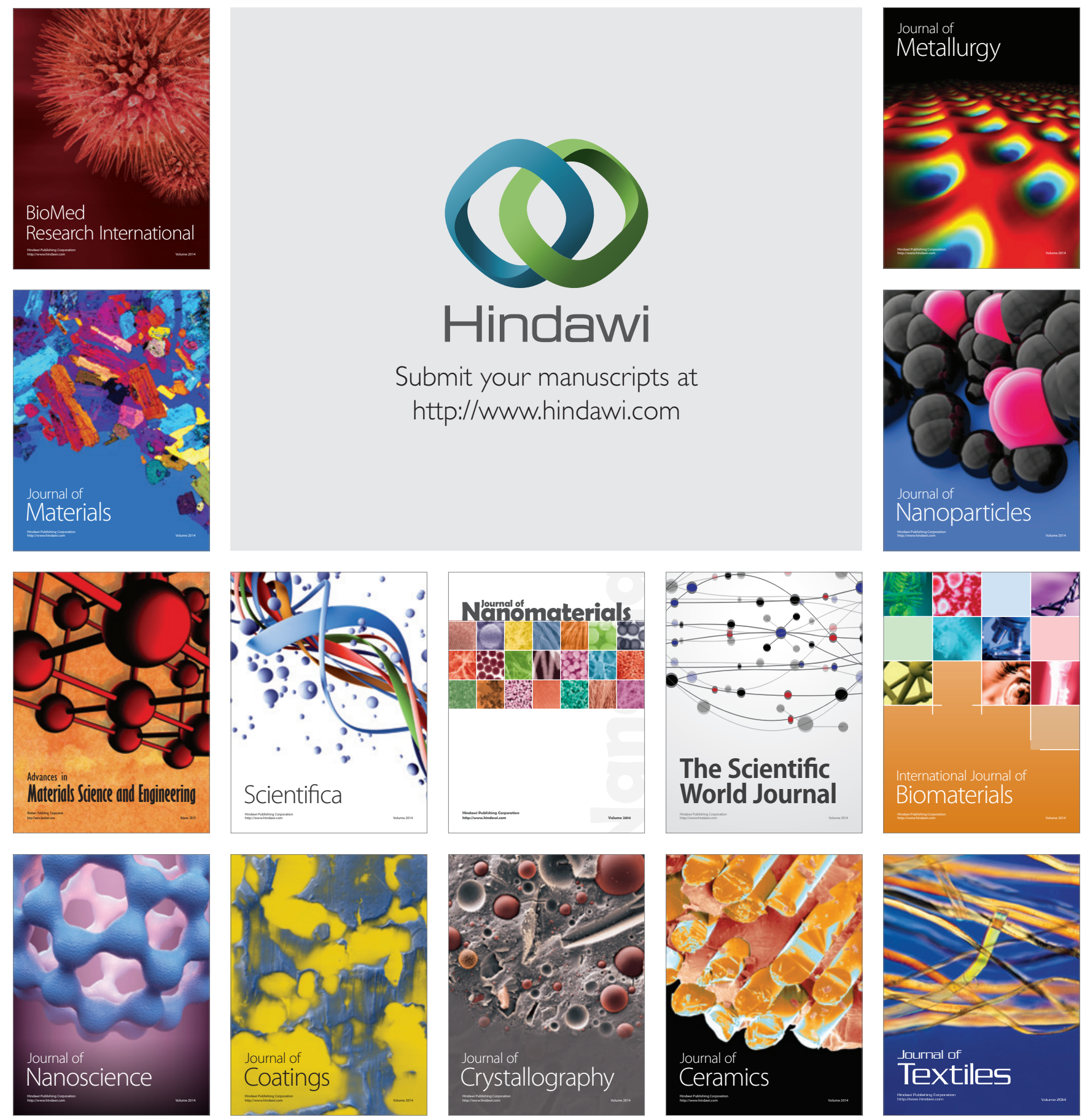